\title{
Algesthesia after Epileptic Seizure
}

\section{J. MARE ̌̌, R. ROKYTA}

Department of Normal, Pathological and Clinical Physiology, Third Faculty of Medicine, Charles University, Prague, Czech Republic

Received April 18, 2007

Accepted December 12, 2007

On-line April 1, 2008

\section{Summary}

The consequences of epileptic seizures related to postictal inhibition in early postictal period include postictal analgesia. We studied this phenomenon over $96 \mathrm{~h}$ following flurothyl-induced seizures in adult male Wistar rats. Nociception of control (no seizure) and seizured groups were tested using the plantar and von Frey hair tests. We determined latency of forepaw and hind paw reactions using plantar tests and the number of von Frey hairs reactions. Shortly after seizures, longer plantar test latencies were seen relative to the control group. Before the seizures the plantar test reaction times were significantly shorter in forepaws than in hind paws. The effect disappeared postseizure and surprisingly, it also disappeared at the corresponding time in controls; it reappeared after $48 \mathrm{~h}$ in the seizure group and after $24 \mathrm{~h}$ in controls. Differences in the von Frey hairs test occurred at 5 and $60 \mathrm{~min}$ post-seizure, however, these differences could not be explained by limb anatomy; although, different thermal and mechanical nociception mechanisms could be significant. The unexpected reactions in controls could be related to brief social and physical interactions between the two groups.

\section{Key words}

Epileptic seizure • Nociception • Flurothyl • Rat • Postictal analgesia

\section{Corresponding author}

R. Rokyta, Department of Normal, Pathological and Clinical Physiology, Third Faculty of Medicine, Charles University, Ke Karlovu 4, 12000 Prague 2, Czech Republic. Fax: +420 224923 827, + 420224916 896. E-mail: richard.rokyta@lf3.cuni.cz

\section{Introduction}

Perception in general, including pain perception, is strongly influenced by the functional status of the brain. Epileptic seizures rarely elicit central pain (Scholz et al. 1999). However, they lead to a variety of postictal phenomena, including changes in somatosensory perception. Decrease in nociception (algesthesia) is usually designated as antinociception. Postictal antinociception (PA) is accepted as an aftereffect of many types of experimentally induced epileptic seizures (Coimbra et al. 2001a,b, Freitas et al. 2004, 2005, Homayoun and Dehpour 2004, Portugal-Santana et al. 2004). The degree of experimentally induced PA is usually evaluated with thermic tests, e.g. tail flick, plantar and hotplate tests (Bocheva and Dzambazova-Maximova 2004, Coimbra et al. 2001a,b, Freitas et al. 2004, 2005). PA effects are usually tested between 30 and $120 \mathrm{~min}$ post-seizure. We were unable to find information describing longer-term PA effects resulting from single epileptic seizures. There is some information in the literature, which along with our previous experiments, suggest a possibility of differential pain sensations in forepaws and hind paws in rats (Yamamotová et al. 2004).

There are many models of epileptic seizures. Seizures are commonly induced by the application of specific drugs or by rhythmic electrical stimulation of the brain. Interpretation of results based on chemically induced epilepsy is complicated by the persistence of the convulsant agent even after the seizure has ended. Therefore, the model of generalized seizures induced by flurothyl - 2,2,2-trifluroethyl ether (Eger et al. 2002) vapors is advantageous because flurothyl is rapidly 
exhaled. The exact mechanism underlying its proconvulsive effect is still under discussion (Hashimoto et al. 2006).

In the presented experiments, we tested shortand long-term changes in sensory functions using the plantar test and the von Frey hairs test. We were also interested to see if there were any differences between forepaw sensation and hind paw sensation and, if these differences existed, to further determine how these differences were affected during the postictal period.

\section{Methods}

The study was carried out on freely moving animals. The animals were raised under a controlled light cycle (12 h light, $12 \mathrm{~h}$ dark, lights on at 6:00 a.m.) with free access to food and water. All procedures were performed in accordance with the Third Faculty of Medicine, Charles University Ethical guidelines and in agreement with the Guidelines of the Animal Protection Law of the Czech Republic, which correspond to the respective EU regulations. The experimental protocol was approved by the Faculty Ethics Committee, and special care was taken to minimize animal suffering.

Adult naive male Wistar rats, obtained from the Anlab breeding farm, $(n=20)$ were randomly assigned to an experimental $(\mathrm{n}=10)$ and a control $(\mathrm{n}=10)$ group. The mean body weight of the rats was $254 \pm 15.6 \mathrm{~g}$. The experimental protocol was performed simultaneously on both the control and the experimental animals. The control animals were exposed to the same procedures as the experimental (i.e. transportation, cages of the same volume, housing). The control animals were tested (plantar test, von Frey hairs test) in the same room, in alternating succession with the experimental animals. Control and experimental animals were housed together in the same room during the entire experiment and were allowed olfactory, auditory and visual contact. With the exception of exposure to flurothyl, the protocol for the control animals was identical to that of the seizured group. Additionally, the duration of procedures was the same for both groups of animals.

\section{Flurothyl seizures}

The experimental animals were placed in an airtight chamber $\left(\begin{array}{ll}14 & 1\end{array}\right)$ with an external air supply. Flurothyl (di-(2,2,2,-trifluoroethyl)ether $-\mathrm{C}_{4} \mathrm{H}_{4} \mathrm{~F}_{6} \mathrm{O}$ ) was administered at a constant rate $(30 \mu \mathrm{l} / \mathrm{min}$; via an infusion pump onto a filter pad suspended at the top of the chamber) until a tonic-clonic seizure was observed. Immediately after the onset of the generalized tonicclonic seizure, the air inside the chamber was exchanged. Seizures ceased within $100.2 \pm 9.2 \mathrm{~s}$ of evacuation of flurothyl vapors. Seizure latencies (time needed to induce a tonic-clonic seizure) were measured. The mean latency ( \pm S.E.M.) was $8 \mathrm{~min} 20 \mathrm{~s} \pm 30 \mathrm{~s}$, which is similar to the values obtained in previous experiments. The animals were then transferred to another room (distant about $18 \mathrm{~m}$ ) where the plantar tests and somatosensory sensitivity (von Frey hairs) tests were conducted. Control animals were placed in similar chamber (without flurothyl vapor) for $10 \mathrm{~min}$. The chamber was not located in the same room where the seizures were evoked.

Please, note that the time at which seizures were induced in the experimental group is an important reference point in time. Other measurements, for both the control and experimental group are made relative to this point in time. Recognize that terms like pre-seizure and post-seizure are used to reference this point, however, only the animals in the experimental group actually experienced a seizure.

The first post-seizure measurements were taken 5 min after the seizure ended. The next measurement was taken $60 \mathrm{~min}$ post-seizure. Subsequent measurements were taken at $24-\mathrm{h}$ intervals, i.e. $24,48,72$ and $96 \mathrm{~h}$ postseizure. The same tests were performed on the control animals at the same, above mentioned, times.

\section{Plantar test}

Pain threshold for thermal stimulation was determined using plantar test equipment (Ugo Basile, Comerio, Italy). The latency (in seconds) of withdrawal to noxious thermal stimulation was measured. We tested all four paws of all animals. Animals were placed individually in a clear plastic box with a clear glass floor. The cut-off value was set at $22 \mathrm{~s}$ to prevent animal injury. The testing box was cleaned between each use.

To minimize any influence the pain threshold test might have on seizures, we measured threshold values, in both, the control and experimental group, $72 \mathrm{~h}$ prior to seizure induction in the experimental group. With regard to this first measurement, the animals were allowed $10 \mathrm{~min}$ to adjust to the test environment before testing began.

\section{von Frey hairs}

In our experiments, the mechanical sensitivity of forepaws and hind paws was measured using following 
von Frey hairs: 4.08, 4.56, 5.07 and 5.88. The presence of mechanical response was evaluated in a binary fashion (0 or 1$)$ in each animal for all hair thicknesses. The average number of all mechanical responses in both groups (control and experimental) for all latencies before and after the seizure was established and statistically compared. This approach expressed changes in sensitivity.

\section{Statistics}

For evaluation of results, we used the two-way repeated-measures ANOVA and one-way repeatedmeasures ANOVA (with Tukey's post-tests) measures. The normality distribution was pretested for each measurement.

\section{Results}

\section{Plantar test}

Control measurements were performed in all animals. We observed significantly different latencies in forepaw and hind paw movements, measured after nociceptive stimulation. After 3 days $(72 \mathrm{~h})$ were animals divided in two groups and flurothyl seizures were elicited in experimental group. The difference between forepaw and hind paw disappeared in this group following seizures, but it reappeared $48 \mathrm{~h}$ later (Table 1). Surprisingly, the difference between hind paw and forepaw sensitivity also disappeared in the control group (Table 1, Fig. 1), when the control animals were tested together with seizured animals. It has been observed at 5 and $60 \mathrm{~min}$ after the seizures were elicited in experimental animals.

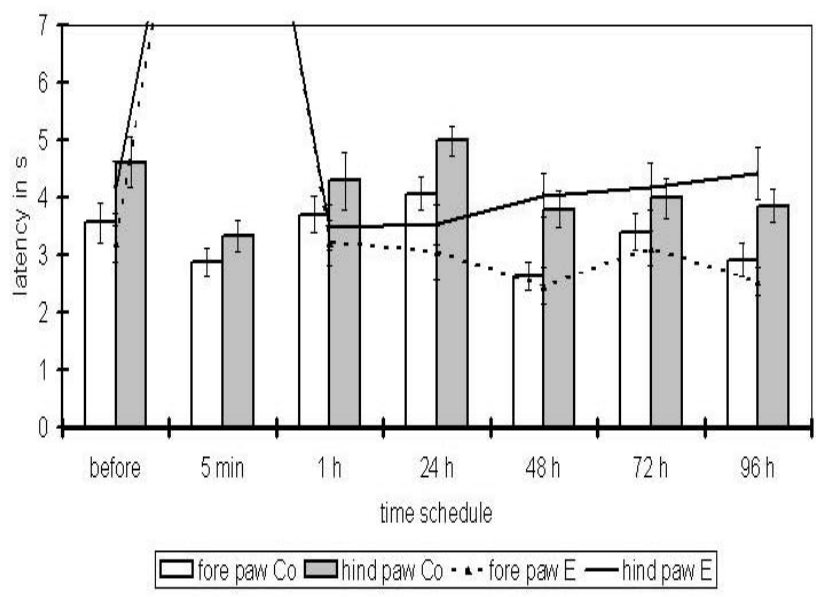

Fig. 1. Comparison of nociception of forepaws and hind paws in plantar tests. Mean latencies in $\mathrm{S} \pm$ S.E.M., Co - control and $\mathrm{E}$ - experimental animals.
In both forepaws and hind paws, significantly longer latencies were found $5 \mathrm{~min}$ post-seizure in the experimental group relative to the control group; at $24 \mathrm{~h}$ post-seizure, the latencies were shorter in experimental group relative to the control group.

We also compared the latencies with repeated measures inside each group (one-way repeated-measures ANOVA - control group: hind paws $\mathrm{P}<0.0005 ; \mathrm{F}=$ $4.801 ; \mathrm{r}^{2}=0.2017$; forepaws $\mathrm{P}<0.0001 ; \mathrm{F}=6.979 ; \mathrm{r}^{2}=$ 0.2686; experimental group: hind paws $\mathrm{P}<0.0001 ; \mathrm{F}=$ $38.27 ; \mathrm{r}^{2}=0.6683$; forepaws $\mathrm{P}<0.0001 ; \mathrm{F}=39.09 ; \mathrm{r}^{2}=$ 0.6729). In a post-hoc test in the experimental group, we observed a significant prolongation of latencies, in both forepaws and hind paws, but only at 5 min post-seizure. However, in the control group, significant prolongations of latencies were seen at one hour and $24 \mathrm{~h}$ post-seizure. These prolongations in the control group were even more conspicuous when comparing plantar test latencies measured at $5 \mathrm{~min}$ post-seizure to the latencies at later scheduled test times.

\section{von Frey hairs}

We did not observe any significant differences between reactions of forepaws and hind paws in control or experimental animals.

However, we did observe significant differences between the experimental group and the control group in the mechanical responses to pressure elicited by all previously mentioned diameters of von Frey hairs $(\mathrm{p}<0.005, \quad \mathrm{~F}=8.787$; two-way repeated-measures ANOVA). This difference was mostly apparent at 5 and 60 min post-seizure (Fig. 2).

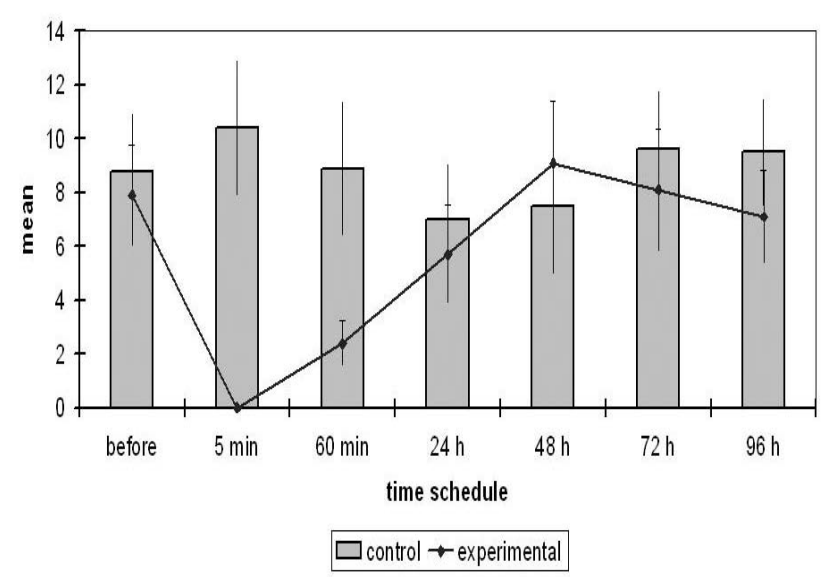

Fig. 2. Mean number ( \pm S.E.M.) of reactions to von Frey hairs elicited 3 days before, and $5 \mathrm{~min}, 1,24,48,72$ and $96 \mathrm{~h}$ after flurothyl-induced seizures. 
Table 1. Comparison of mean latencies (plantar test) between forepaws and hind paws and the differences between the mean numbers of reactions to von Frey hairs.

\section{Plantar test}

\begin{tabular}{|c|c|c|c|c|c|c|c|}
\hline \multirow{2}{*}{$\begin{array}{l}\text { Fore - vs. } \\
\text { hind paws }\end{array}$} & \multirow{2}{*}{$\begin{array}{l}\text { before } \\
\text { seizure }\end{array}$} & \multicolumn{6}{|c|}{ after seizure in experimental group } \\
\hline & & $5 \mathrm{~min}$ & $1 \mathrm{~h}$ & $24 \mathrm{~h}$ & $48 \mathrm{~h}$ & $72 \mathrm{~h}$ & $96 \mathrm{~h}$ \\
\hline \multicolumn{8}{|l|}{ Experiment } \\
\hline Forepaws & $\begin{array}{c}3.21 \pm 0.32 \\
*\end{array}$ & $\begin{array}{c}14.41 \pm 2.61 \\
\mathrm{NS}\end{array}$ & $\begin{array}{c}3.23 \pm 0.39 \\
\mathrm{NS}\end{array}$ & $\begin{array}{c}3.06 \pm 0.47 \\
\mathrm{NS}\end{array}$ & $\begin{array}{c}2.47 \pm 0.31 \\
*\end{array}$ & $\begin{array}{c}3.13 \pm 0.31 \\
*\end{array}$ & $\begin{array}{c}2.55 \pm 0.24 \\
*\end{array}$ \\
\hline Hind paws & $4.18 \pm 0.45$ & $14.07 \pm 2.59$ & $3.49 \pm 0.39$ & $3.55 \pm 0.35$ & $4.05 \pm 0.37$ & $4.20 \pm 0.42$ & $4.43 \pm 0.45$ \\
\hline \multicolumn{8}{|l|}{ Control } \\
\hline Forepaws & $\begin{array}{c}3.57 \pm 0.35 \\
*\end{array}$ & $\begin{array}{c}2.88 \pm 0.25 \\
\mathrm{NS}\end{array}$ & $\begin{array}{c}3.72 \pm 0.33 \\
\mathrm{NS}\end{array}$ & $\begin{array}{c}4.08 \pm 0.29 \\
*\end{array}$ & $\begin{array}{c}2.64 \pm 0.24 \\
*\end{array}$ & $\begin{array}{c}3.40 \pm 0.32 \\
*\end{array}$ & $\begin{array}{c}2.93 \pm 0.3 \\
*\end{array}$ \\
\hline Hind paws & $4.63 \pm 0.44$ & $3.33 \pm 0.28$ & $4.30 \pm 0.51$ & $5.00 \pm 0.26$ & $3.8 \pm 0.33$ & $4.00 \pm 0.35$ & $3.87 \pm 0.29$ \\
\hline
\end{tabular}

\section{von Frey hairs}

\begin{tabular}{|c|c|c|c|c|c|c|c|}
\hline & \multirow{2}{*}{$\begin{array}{l}\text { before } \\
\text { seizure }\end{array}$} & \multicolumn{3}{|c|}{ after seizure in experimental group } & \multirow[b]{2}{*}{$48 \mathrm{~h}$} & \multirow[b]{2}{*}{$72 \mathrm{~h}$} & \multirow[b]{2}{*}{$96 \mathrm{~h}$} \\
\hline & & 5 min & $1 \mathrm{~h}$ & $24 \mathrm{~h}$ & & & \\
\hline \multirow[t]{2}{*}{ Experiment } & $7.9 \pm 1.88$ & 0 & $2.4 \pm 0.85$ & $5.7 \pm 1.8$ & $9.1 \pm 2.28$ & $8.1 \pm 2.27$ & $7.1 \pm 1.75$ \\
\hline & NS & $*$ & $*$ & NS & NS & NS & NS \\
\hline Control & $8.8 \pm 2.176$ & $10.4 \pm 2.51$ & $8.9 \pm 2.51$ & $7.0 \pm 2.08$ & $7.5 \pm 2.52$ & $9.6 \pm 2.21$ & $9.5 \pm 2.00$ \\
\hline \multicolumn{8}{|c|}{ Experimental group - significant differences } \\
\hline Before & & $*$ & * & NS & NS & NS & NS \\
\hline $5 \min$ & * & & * & * & $*$ & $*$ & $*$ \\
\hline $1 \mathrm{~h}$ & $*$ & $*$ & & NS & $*$ & $*$ & NS \\
\hline
\end{tabular}

Plantar test: numbers represent mean latencies \pm S.E.M. in seconds; von Frey Hairs: mean numbers of reactions \pm S.E.M.; $* p<0.05$; NS - non-significant.

In the group of control animals we did not find any significant differences related to repetition of measurements $\left(\mathrm{F}=1.118 ; \mathrm{r}^{2}=0.1105\right.$; one-way repeatedmeasures ANOVA). In the experimental group of animals we observed significant differences in means $(\mathrm{P}<0.0001 ; \mathrm{F}$ $=6.669 ; \quad r^{2}=0.4256 ;$ one-way repeated-measures ANOVA). Differences between individual measurements (times relative to the start of experiment) (Fig. 2, Table 1).

\section{Discussion}

Antinociception occurs following epileptic tonic-clonic seizures in both experimental animals and humans. Other sensory inputs are also altered. Mechanisms involved in postictal antinociception remain to be explained in detail. Duration of sensory changes may correlate with postictal changes in transmitter systems.

The postictal period is characterized by many short- and long-lasting functional changes in the brain. Postictal inhibition is a prominent phenomena directly linked to the end of the seizure. It is difficult to induce another epileptic seizure during this period (Mareš et al. 1982). Some functional changes during the postictal phase are usually explained by the persistence of the increased inhibition that occurs at the end of a seizure. Changes in extracellular concentrations of various substances may also play an important role. Many of these substances could be related to antinociception; for example increases in the extracellular concentration of adenosine (During and Spencer 1992, Kulkarni et al. 1994, 1997), opioid peptides or amino acids (Engel and 
Rocha 1992, Halonen et al. 1992, Rocha et al. 1991, Velíšek and Mareš 1992). Adenosine decreases nociceptive perception in both animals and in humans. It acts both centrally and peripherally (Chizh et al. 2004, Hayashida et al. 2005). GABA has been shown to have anticonvulsant as well as antinociceptive effects (McGaraughty et al. 2005). Several compounds formerly considered as GABAergic are specifically used for the treatment of neuropathic pain, e.g. gabapentin and pregabalin with different mechanism for each of them (Backonja 2002, McGaraughty et al. 2005). These compounds bind to specific subunit of voltage-gated calcium channels and modulate release of transmitters (Maneuf et al. 2006, Taylor et al. 2007). Therefore, there is little doubt that opioid peptides are involved in postictal antinociception (Portugal-Santana et al. 2004).

Our results support the hypothesis that antinociception is closely related to the above-mentioned substances. It has been demonstrated that changes in their concentrations occur after epileptic seizures and these changes have been shown to last for tens of minutes (Freitas et al. 2004, 2005, Portugal-Santana et al. 2004). Consistent with the above, we observed that the period of decreased sensitivity following a seizure was short. On the other hand, comparison with control animals revealed an interesting increase in sensitivity $24 \mathrm{~h}$ post-seizure. These results suggest the existence of long-lasting changes that cannot be explained by changes in concentrations of the above mentioned substances. In our other experiments with flurothyl-induced seizures (Mareš et al. 2004), we observed changes in learning (associated with a water maze) $24 \mathrm{~h}$ post-seizure. Because of the oxidative stress related to seizures (Patel 2002) these long-lasting changes could be related to changes in free radical concentrations that occur during a seizure. Oxidative stress, as measured by free radicals and singlet oxygen, is one possible explanation for increased nociception following either acute or chronic painful stimulation (Rokyta et al. 2003, 2004). Additionally, it has been shown that the increased nociception can be reduced with antioxidants. The antinociceptive mechanism in our model of postictal changes is dominant during the early postictal period. The question is whether the increase of reactive oxygen species (ROS) levels during a seizure may cause increased sensitivity $24 \mathrm{~h}$ post-seizure relative to controls. It is known that ROS act as mediators for the activation of processes connected to apoptosis and also as growth signals (Min et al. 2006). It may elucidate some delayed functional changes. It is not clear whether ROS have some immediate direct functional effect.

The difference in sensitivity of forepaws and hind paws in intact rats is rarely mentioned in the literature (Morgan and Whitney 1996, Yamamotová et al. 2004). Our results support the suggestion of a different mechanism of nociception for forepaws and hind paws (Yamamotová et al. 2004). This has been explained by the involvement of different receptor-transmitter systems. Nociception in forepaws is preferentially influenced by the opioid antinociceptive system, while nociception in hind paws is more influenced by the system sensitive to non-steroidal anti-inflammatory drugs (Hirate et al. 2006, Lewis 1986). The fact that the forepaw/hind paw difference was still absent $24 \mathrm{~h}$ post-seizure in our experimental group indicates the fragility of these systems of sensation. The loss of this difference in nociceptive sensitivity, in the control group, at the same time when the experimental animals underwent induced seizures and entered the postictal period was surprising. As was already mentioned in the method section, the experimental and control animals were in contact during the postictal period. We hypothesize that olfaction was, most probably, the sensory modality responsible for the coincidental and analogous change in nociceptive sensitivity seen in the controls (Kavaliers et al. 1998). However, it does not explain the nature of the phenomenon. The control group also exhibited changes in latencies of reactions of both forepaws and hind paws in the plantar test when compared with subsequent measurements. The explanation of this phenomenon could be similar, i.e. olfactory, visual and auditory contact with the experimental group.

The cranial-caudal difference between forepaws and hind paws revealed by the plantar test was not observed when the animals were tested using von Frey hairs. Anatomical differences alone are not sufficient to explain the results seen in the von Frey test. Post-seizures changes in latencies lasted longer than in plantar test. Additionally, there was no increased sensitivity in experimental animals $24 \mathrm{~h}$ post-seizure, nor was there decreased sensitivity in control animals as was seen in the plantar test at the corresponding time. This supports the idea that both modalities (somatosensory and thermal) are governed by different systems.

Our results demonstrate that nociception, as measured by the plantar test, can be influenced, by a simple short epileptic seizure, for up to $24 \mathrm{~h}$ post-seizure. Hypoesthesia, relative to controls, occurred shortly after 
seizures (5 min post-seizure) in experimental animals and had transitioned to hyperesthesia, relative to controls, $24 \mathrm{~h}$ post-seizure. We used plantar test to estimate the difference in pain perception between forepaws and hind paws. This difference disappears $24 \mathrm{~h}$ post-seizure. Differences between forepaws and hind paws were not observed during testing with von Frey hairs. This shows that the difference between the forepaws and hind paws can not be explained by differences in anatomy between paws. It suggests that different mechanisms of thermal and mechanical nociception might play an important role.
The reaction of the control group to the induced seizures in the experimental group illustrates a sensitivity of perception along other parameters. Further research into this intriguing phenomenon may result in some very interesting and surprising findings.

\section{Conflict of Interest}

There is no conflict of interest.

\section{Acknowledgements}

This work was supported by MSM RG 0021620816.

\section{References}

BACKONJA MM: Use of anticonvulsants for treatment of neuropathic pain. Neurology 59: S14-17, 2002.

BOCHEVA AI, DZAMBAZOVA-MAXIMOVA EB: Effects of kyotorphin and analogues on nociception and pentylenetetrazole seizures. Folia Med (Plovdiv) 46: 40-44, 2004.

CHIZH BA, DUSCH M, PUTHAWALA M, SCHMELZ M, COOKSON LM, MARTINA R, BROWN J, KOPPERT $\mathrm{W}$ : The effect of intravenous infusion of adenosine on electrically evoked hyperalgesia in a healthy volunteer model of central sensitization. Anesth Analg 99: 816-822, 2004.

COIMBRA NC, CASTRO-SOUZA C, SEGATO EN, NORA JE, HERRERO CF, TEDESCHI-FILHO W, GARCIACAIRASCO N: Post-ictal analgesia: involvement of opioid, serotoninergic and cholinergic mechanisms. Brain Res 888: 314-320, 2001a.

COIMBRA NC, FREITAS RL, SAVOLDI M, CASTRO-SOUZA C, SEGATO EN, KISHI R, WELTSON A, RESENDE GC: Opioid neurotransmission in the post-ictal analgesia: involvement of $\mu_{1}$-opioid receptor. Brain Res 903: 216-221, 2001b.

DURING MJ, SPENCER DD: Adenosine: a potential mediator of seizure arrest and postictal refractoriness. Annals of Neurology 32: 618-624, 1992.

EGER EI, GONG D, XING Y, RAINES DE, FLOOD P: Acetylcholine receptors and thresholds for convulsions from flurothyl and 1,2-dichlorohexafluorocyclobutane. Anesth Analg 95: 1611-1615, table of contents, 2002.

ENGEL JJ, ROCHA LL: Interictal behavioral disturbances: a search for molecular substrates. Epilepsy Research. Supplement 9: 341-349, 1992.

FREITAS RL, DE OLIVEIRA RC, DE CARVALHO AD, FELIPPOTTI TT, BASSI GS, ELIAS-FILHO DH, COIMBRA NC: Role of muscarinic and nicotinic cholinergic receptors in an experimental model of epilepsyinduced analgesia. Pharmacol Biochem Behav 79: 367-376, 2004.

FREITAS RL, FERREIRA CM, RIBEIRO SJ, CARVALHO AD, ELIAS-FILHO DH, GARCIA-CAIRASCO N, COIMBRA NC: Intrinsic neural circuits between dorsal midbrain neurons that control fear-induced responses and seizure activity and nuclei of the pain inhibitory system elaborating postictal antinociceptive processes: a functional neuroanatomical and neuropharmacological study. Exp Neurol 191: 225-242, 2005.

HALONEN T, PITKÄNEN A, PARTANEN J, HYTTINEN JM, RIEKKINEN PJ: Amino acid levels in cerebrospinal fluid of rats after administration of pentylenetetrazol. Comp Biochem Physiol C 101: 21-25, 1992.

HASHIMOTO Y, ARAKI H, SUEMARU K, GOMITA Y: Effects of drugs acting on the GABA-benzodiazepine receptor complex on flurothyl-induced seizures in Mongolian gerbils. Eur J Pharmacol 536: 241-247, 2006.

HAYASHIDA M, FUKUDA K, FUKUNAGA A: Clinical application of adenosine and ATP for pain control. J Anesth 19: 225-235, 2005.

HIRATE K, UCHIDA A, OGAWA Y, ARAI T, YODA K: Zaltoprofen, a non-steroidal anti-inflammatory drug, inhibits bradykinin-induced pain responses without blocking bradykinin receptors. Neurosci Res 54: 288-294, 2006. 
HOMAYOUN H, DEHPOUR AR: Differential contribution of cholecystokinin receptors to stress-induced modulation of seizure and nociception thresholds in mice. Pharmacol Biochem Behav 78: 209-215, 2004.

KAVALIERS M, COLWELL DD, CHOLERIS E: Analgesic responses of male mice exposed to the odors of parasitized females: effects of male sexual experience and infection status. Behav Neurosci 112: 1001-1011, 1998.

KULKARNI C, DAVID J, JOSEPH T: Involvement of adenosine in postictal events in rats given electroshock. Indian $J$ Physiol Pharmacol 38: 39-43, 1994.

KULKARNI C, DAVID J, JOSEPH T: Influence of adenosine, dipyridamole, adenosine antagonists and antiepileptic drugs on EEG after discharge following cortical stimulation. Indian J Physiol Pharmacol 35: 342-347, 1997.

LEWIS JW: Multiple neurochemical and hormonal mechanisms of stress-induced analgesia. Ann N Y Acad Sci 467: 194-204, 1986.

MANEUF YP, LUO ZD, LEE K: $\alpha_{2} \delta$ and the mechanism of action of gabapentin in the treatment of pain. Semin Cell Dev Biol 17: 565-570, 2006.

MAREŠ J, MAREŠ P, KADLECOVÁ-JURSÍKOVÁ D: Changes in the excitability of rat cerebral cortex after a selfsustained after-discharge. Electroencephalogr Clin Neurophysiol 53: 283-288, 1982.

MAREŠ J, POMETLOVÁ M, KRÝSL D, ROKYTA R: Effect of pretreatment of melatonin on impaired learning after epileptic seizure elicited by flurothyl. Physiol Res 53: 23P, 2004.

MCGARAUGHTY S, COWART M, JARVIS MF, BERMAN RF: Anticonvulsant and antinociceptive actions of novel adenosine kinase inhibitors. Curr Top Med Chem 5: 43-58, 2005.

MIN JY, PARK MH, PARK MK, PARK KW, LEE NW, KIM T, KIM HJ, LEE DH: Staurosporin induces neurite outgrowth through ROS generation in HN33 hippocampal cell lines. J Neural Transm 113: 1821-1826, 2006.

MORGAN MM, WHITNEY PK: Behavioral analysis of diffuse noxious inhibitory controls (DNIC): antinociception and escape reactions. Pain 66: 307-312, 1996.

PATEL MN: Oxidative stress, mitochondrial dysfunction, and epilepsy. Free Radic Res 36: 1139-1146, 2002.

PORTUGAL-SANTANA P, DORETTO MC, TATSUO MA, DUARTE ID: Involvement of prolactin, vasopressin and opioids in post-ictal antinociception induced by electroshock in rats. Brain Res 1003: 1-8, 2004.

ROCHA L, ENGEL J, JEROME, ACKERMANN RF: Effects of chronic naloxone pretreatment on amygdaloid kindling in rats. Epilepsy Res 10: 103-110, 1991.

ROKYTA R, HOLEČEK V, PEKÁRKOVÁ I, KREJČOVÁ J, RACEK J, TREFIL L, YAMAMOTOVÁ A: Free radicals after painful stimulation are influenced by antioxidants and analgesics. Neuro Endocrinol Lett 24: 304309, 2003.

ROKYTA R, STOPKA P, HOLEČEK V, KŘIKAVA K, PEKÁRKOVÁ I: Direct measurement of free radicals in the brain cortex and the blood serum after nociceptive stimulation in rats. Neuro Endocrinol Lett 25: 252-256, 2004.

SCHOLZ J, VIEREGGE P, MOSER A: Central pain as a manifestation of partial epileptic seizures. Pain 80: 445-450, 1999.

TAYLOR CP, ANGELOTTI T, FAUMAN E: Pharmacology and mechanism of action of pregabalin: the calcium channel $\alpha_{2}-\delta$ (alpha $a_{2}$-delta) subunit as a target for antiepileptic drug discovery. Epilepsy Res 73: 137-150, 2007.

VELISEK L, MARES P: Differential effects of naloxone on postictal depression. Epilepsy Res 12: 37-43, 1992.

YAMAMOTOVÁ A, BUBENÍKOVÁ V, ROKYTA R, ŠŤASTNÝ F: Comparison of phenotype of pain in two neurodevelopmental models of schizophrenia in rats (in Czech). Psychiatrie 8: 25-28, 2004. 